\title{
Influence of Brand Value on the Increase of Marketing Earnings
}

\section{Xun LI}

Department of Management Engineering, Dalian University of Science and Technology, Dalian, Liaoning 116052

lian004@163.com

Keywords: Brand, Brand Value, Increase of Marketing Earnings

\begin{abstract}
Brand value plays a very important role in the development of enterprises. Literally, it can be seen that brand value refers to the value, which is reflected through the prices. However, the intension of it is far more than this. In this paper, the intension of brand value is introduced first, and then the influence of brand value on the increase of marketing earnings is discussed. Therefore, this paper is of reference and practical values.
\end{abstract}

\section{Introduction}

As the economic globalization continuously develops with each passing day, market competition has been proven to be a focus of the new competitions at the international market. According to the statistics made by the United Nations Industrial Programme, the products of less than 3\% world famous brands took up more than $40 \%$ of global market shares, and also their sales amount accounted for $50 \%$ of the total sales at the global market. There have been plenty of reasons to prove that the modern people have stepped into an age of brand.

However, the value of brand has not been recognized by a great number of people although brand has become an indispensable part of the life of people. Literally, it can be seen that brand value refers to the value, which is reflected through the prices. However, the intension of it is far more than this. In this paper, the intension of brand value is introduced first, and then the influence of brand value on the increase of marketing earnings is discussed. Therefore, this paper is of reference and practical significance.

\section{Intensions of Brand and Brand Value}

\subsection{Intension of Brand}

The intension of brand is the foundation for studying brand value. According to the definition from American Marketing Association, brand refers to a name, a proper noun, a mark, a symbol, or a design, which is used for identifying the products and services of dealers or sales groups and also making them different from the products and services of other competitors. According to this definition, brand is a representative of specific organization, product, and service, and symbolizes their intensions. Importantly, it is necessary for a brand to make an enterprise as well as products and services different from its competitors from the visual and auditory senses and other identifiable aspects. Along with the developments of modern society and commodity economy, the importance of brand for an enterprise has exceeded the functions of a sign or a symbol; the powerful brands have been proven to be the symbols of enterprise market position and the guarantees of competitive advantages. For this reason, the due importance is necessarily attached to brand.

\subsection{Intension of Brand Value}

The reason why brand is with value is that value can be created by brand. Therefore, increasingly higher importance has been attached by enterprises to brand value, and even is thought to be the most valuable property of an enterprise. Brand value usually refers to the intrinsic value of a brand; in terms of qualitative analysis, the value of a brand mainly comprises of cost value, relationship value, and power value. 
The "cost" value of a brand refers to the value, which is produced from the investment in all monetary and nonmonetary forms of brand. In terms of enterprise, cost is always necessary in the process from a brand's naming, designing and applying and registering for trademark to forming a powerful brand with high popularity. In the meantime, with the purpose of beating the competitors and striving for the customers, it is also necessary for an enterprise to invest a large amount of capitals and labors in opening up market, enlarging market share, carrying out advertising and promotion, constructing and managing marketing channels, etc. All the effective work invested by an enterprise in the marketing activities is a source of cost value of brand.

The "relationship value" of a brand refers to the investment in establishing, maintaining and developing a long-term relationship between a brand and its customers and the subsequent value reflected from the benefits brought by customers and enterprises. The fundamental reason why the relationship with customers is very important and valuable is that a huge investment is necessary for the establishment and development of the relationship with customers in the age of brand competition, but part of this investment will become the cost value of brand and the left will become the relationship value of brand. The value reflected from the benefits of two sides constitutes the "relationship value" of a brand.

The "power" value of a brand refers to the value, which is reflected from the benefits obtained through the performance and use of brand power. In the real economic life, the typical expression to the "power" value of a brand is the bargained transfer of the exclusive right to use trademark, and the transfer fee is a specific embodiment of the "power" value of brand. Because most powerful brands have been well-known, consumers buy the products of these famous brands not only for obtaining the products' physical function or use function, but also for hunting the reputation and authority of the products and meeting the mental needs. With the purpose of buying reputation and authority, corresponding costs are also paid by consumers. All these are important sources of power brand value.

From above analysis, brand value is with very rich and profound intension. Therefore, in the process of recognizing brand value, it can't be evaluated unilaterally, because this will hinder the exertion of its functions.

\section{Influence of Brand Value on the Increase of Marketing Earnings}

With China's sustained economic development, the living standards of people have been improved significantly, and simultaneously the industries in society are undergoing a stage from quantitative change to qualitative change.

Brand has changed into the most significant representative of enterprise comprehensive competitiveness. Meanwhile, increasingly higher importance is attached by entrepreneurs to brand value, and many large enterprises successively begin to promote marketing by using brand value.

However, what influences will brand value exert on the increase of marketing earnings? This can be embodied in the following aspects.

\subsection{Preventing Product Homogeneity between Enterprises}

From the above analysis, it can be known that brand is with a very rich intension, which is not only symbol and name, but also contains vivid spiritual cultural contents; brand gives an expression to the value of people, symbolizes the social status of people, and also can voice the feelings of people.

However, brand value owns three aspects of contents, which are cost, relationship, and power, and also it is the final "protective screen" for preventing the enterprises from falling into simple product homogeneity price competition. As is known to all, the product, quality, technology, management, channel, service and process of an enterprise are very easy to be imitated by its competitors. However, a brand as well its value can never be copied by the competitors. The naming and logo designing of a brand are only the first step for the building of brand value.

To give a real reflection to the value of a remarkable brand, it is still necessary to make brand investigation diagnosis, brand planning orientation, brand promotion and brand adjustment 
evaluation, but also improve the popularity, reputation and loyalty of brand and accumulate brand equity. In such a way, brand value helps the enterprise prevent product homogeneity, highlights the unique features of the enterprise, and thus brings about the increase of enterprise marketing earnings.

\subsection{Improving the Market Identification of Enterprise}

Generally speaking, an enterprise will upgrade its business to the level of brand competition after attaining certain developments. The intension of brand competition is extremely rich, and mainly can be reflected from three aspects: (1) the competition of product form brand; (2) the competition of product line brand; (3) the competition of company brand. In all stages, the key is the competition of brand value, which is the purpose and significance of the existence of brand and also suggests an enterprise can provide values for consumers. The recognition of consumers on brand from the concept is the core demand of consumers on brand and also the fundamental reason for consumers to keep loyalty to brand. Good brand value can help enterprise attract the attention of consumers on products, and thus an improvement can be made to the market identification of enterprise and good economic benefits and benefits can be obtained by enterprise as well.

\subsection{Constructing the Long-term Loyalty of Consumers}

In the age of new economy, the unique advantages of product category are difficult to be maintained for a long time, the demands of consumers are continuously changing-over, and also the concrete products are hard to get loyalty from consumers. Therefore, it is necessary for products to be innovative for meeting the demands of consumers. However, it is difficult for the competitors to go beyond the brand values of the products. If brand value of product can be continuously updated by an enterprise, consumers can be promoted to be loyal to the product for a long time, and simultaneously product marketing rate can be greatly improved.

In short, brand value has many benefits to the increase of the marketing earnings of enterprises, and it is necessary for enterprise to know well the roles of brand and brand value and bring their functions into play to the maximum. In this way, the sustainable development of enterprises can be greatly promoted.

\section{References}

[1] YunBo Qu, Wei Liu. Important Eighteen Rules of Brand Marketing [J]. Enterprise Management, 2006, (02).

[2] Jianxin Wang. Brand Loyalty and Brand Value [J]. China Trademark, 2007, (05).

[3] Lingcheng Kong, Xueping Wang. Discussion on the Analysis and Evaluation of Brand Value [J]. Economic Forum, 2015, (22).

[4] Jiyin Zhong. Brand Marketing: The Most Intense Field in the Modern Market Competition [J]. China Trademark, 2 